\title{
Caries into Dentin
}

National Cancer Institute

\section{Source}

National Cancer Institute. Caries into Dentin. NCI Thesaurus. Code C94555.

Tooth decay that extends through the enamel into the dentin layer. 